ISSN: $2317-8957$

Volume 5, Number 1, Jun. 2017

\title{
EDUCAÇÃO FÍSICA E MONTANHISMO \\ UM CONTEÚDO POSSÍVEL NA ESCOLA?
}

\author{
FERNANDO MARLOS BARBOSA ${ }^{1}$, MARCELO PARAÍSO ALVES ${ }^{2,3}$, FÁBIO MURAT DO PILLAR ${ }^{3}$, \\ CASSIO MARTINS ${ }^{2}$
}

${ }^{1}$ Prefeitura municipal de Piraí/RJ

2 Centro Universitário de Volta Redonda (UniFOA)

3 Instituto Federal de Educação, Ciência e Tecnologia do Rio de Janeiro (IFRJ)

\begin{abstract}
RESUMO
O presente estudo emerge do diálogo entre dois campos do saber: Educação Física Escolar e Educação Ambiental. Tal entrelaçamento deve-se a intenção de construir uma cultura sobre o processo das práticas corporais (Educação Física) e da educação ambiental, a fim de caminhar, de modo que de reprodutor de uma relação meramente conservadora se torne, neste processo, articulador do desafio que assumimos como fio condutor - o enfrentamento à Armadilha Paradigmática. Diante desse contexto, objetivamos visibilizar as fabricações cotidianas dos praticantes que produzem um currículo peculiar a partir dos conteúdos oficialmente estabelecidos para a Educação Física. A pesquisa foi realizada no município de Porto Real, situado no estado do Rio de Janeiro. A pesquisa ora apresentada utilizou o Estudo do Cotidiano como percurso teórico-metodológico.
\end{abstract}

Palavras-chave: Montanhismo, Educação Física, Educação Ambiental Crítica.

\begin{abstract}
The present study emerges from the dialogue between two fields of knowledge: School Physical Education and Environmental Education. Such intertwining is due to the intention of constructing a culture about the process of physical practices (physical education) and of environmental education, in order to walk, so that reproducing a merely conservative relationship becomes, in this process, articulator of the challenge which we assume as the guiding thread - the confrontation with the Paradigm Trap. Given this context, we aim to make visible the daily productions of practitioners who produce a peculiar curriculum from the officially established contents for Physical Education. The research was carried out in the municipality of Porto Real, located in the state of Rio de Janeiro. The research presented here used the Daily Life Study as a theoretical-methodological course.
\end{abstract}

Keywords: Mountaineering, Physical Education, Critical Environmental Education.

\section{INTRODUÇÃO}

O presente estudo emerge do diálogo entre dois campos do saber: Educação Física Escolar e Educação Ambiental. Tal entrelaçamento deve-se a intenção de construir uma cultura sobre o processo das práticas corporais (Educação
Física) e da Educação Ambiental Crítica, a fim de caminhar, de modo que de reprodutor de uma relação meramente conservadora se torne, neste processo, articulador do desafio que assumimos como fio condutor - o enfrentamento à Armadilha Paradigmática (GUIMARÃES, 2004). Cabe frisar, que este estudo 
buscou as ações pedagógicas de uma instituição privada localizada no interior do estado do Rio de Janeiro, na tentativa de visibilizar as práticas cotidianas desenvolvidas nas unidades educacionais e que, em diversos momentos, são consideradas como lazer, entretenimento, cultura, no entanto, desprovidas de conhecimentos.

Na trajetória histórica da Educação Física brasileira, temos nos deparado com a diversidade de práticas oriundas dos aspectos políticos, sociais, econômicos e culturais que os produziram, como por exemplo: a ênfase no corpo forte e limpo, o robustecimento corporal com ênfase no espaço fabril, a eficácia e eficiência no gesto esportivo no intuito de alcançar a melhor performance, dentre outros (BETTI; ZULIANI, 2002).

Os autores ainda mencionam que em detrimento destas práticas corporais, nos últimos anos a Educação Física escolar buscou a referência no esporte, tornando-se um produto a ser consumido por um público significativo.

Para Moreira, Simões e Martins (2010) alguns docentes buscam práticas corporais alternativas, no intuito de ampliar a docência na escola para além das práticas do Futsal, Voleibol, Handebol e o Basquetebol.

Nesta linha de pensamento, a presente pesquisa emerge articulada ao Estudo do Cotidiano (ALVES; GARCIA, 2008; FERRAÇO, PEREZ, OLIVEIRA, 2008; OLIVEIRA, 2003; 2008; 2012; CERTEAU, 1994; SANTOS, 2002; 2004) na intenção de desinvisibilizar experiências antes silenciadas pelas pesquisas tradicionais.

O estudo apresenta as práticas socioculturais que emergem do currículo de uma instituição que atua com alunos da Educação Básica, bem como com as possibilidades concretas e radicais na expectativa de construção de ações que abram caminhos para novos processos emancipatórios - Sociologia das Emergências (SANTOS, 2004).

Diante desse contexto, objetivamos visibilizar as fabricações cotidianas dos praticantes que produzem um currículo peculiar a partir dos conteúdos oficialmente estabelecidos para a E- ducação Física. Assim cabe salientar que o estudo está articulado à noção de currículo "pensadopraticado" "(OLIVEIRA, 2012).

\section{FUNDAMENTOS TEÓRICO- METODOLÓGICOS}

A pesquisa foi realizada no município de Porto Real, situado no estado do Rio de Janeiro. O município localiza-se na Mesorregião Sul Fluminense do estado do Rio de Janeiro, estando a uma altitude de 385 metros. Possui uma população de aproximadamente 17.000 habitantes, segundo o Censo 2010.

A unidade educacional investigada atende aos alunos da Educação Infantil (Maternal I, II e III, Pré - I e II), no período matutino e vespertino. Os alunos do Ensino Fundamental $\left(1^{\circ}\right.$ ao $9^{\circ}$ ano) podem optar pelo período matutino e vespertino. E, por fim, alunos do Ensino Médio $\left(1^{\mathrm{o}}, 2^{\mathrm{o}}\right.$ e $3^{\mathrm{o}}$ ano $)$ com aulas apenas no período matutino, atendendo alunos de classe média do município de Porto Real.

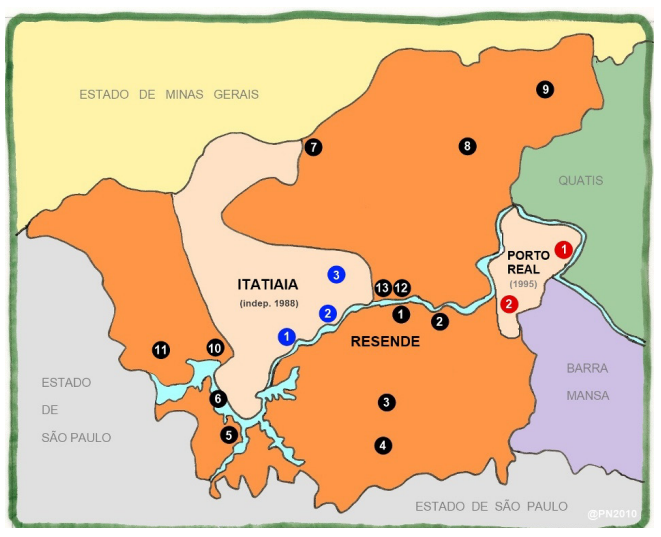

Figura 1: Mapa geográfico da Região da Mesorregião Sul Fluminense (http://agenciaspostais.com.br/?page $\mathrm{id}=320$ ).

A pesquisa ora apresentada utilizou o Estudo do Cotidiano como percurso teórico-me

${ }^{1}$ A grafia a partir da junção de palavras emerge da aproximação que estabeleço com a perspectiva de Garcia e Alves (2008) e da uma opção teórico-metodológica que consciente dos limites que temos de nossa formação acadêmica (moderna), dicotômica, nos deixou um legado de termos que isoladamente são insuficientes para compreender os cotidianos. 
todológico. Nesse sentido, a discussão proposta se aproximou da perspectiva de Alves (2003) que propõe movimentos para pesquisa diferenciados do que os aprendidos na modernidade. Para a autora, existe um modo de fazer e de criar conhecimentos no cotidiano diferente daquele proposto pela razão moderna.

Alves (2003) entende que contrariamente ao que propõem as "ciências surgidas na Modernidade, essas maneiras incluem de modo inseparável, o fazerpensar ${ }^{2}$, tanto como a práticateoriaprática, em movimentos sincrônicos que misturam sempre agir, dizer,criar, lembrar, sentir" (p. 2).

Diante do exposto, a teoria proposta por Santos $(2002 ; 2004 ; 2006 ; 2007)$ se aproxima de tal perspectiva por possuir uma ótica que emerge da razão cosmopolita: Sociologia das Ausências, a Sociologia das Emergências e a Ecologia dos Saberes.

Tal proposta de investigação emerge das práticas invisíveis na tentativa de tornar credíveis ações marginalizadas no âmbito social, no caso deste, os cotidianos escolares.

Assim, na possibilidade de estabelecer o movimento teórico epistemológico e metodológico o estudo realizou duas ações complementares: primeira, a realização de uma pesquisa de cunho bibliográfico, como levantamento dos materiais para o estudo - livros, teses e artigos de revistas especializadas -, mais especificamente em relação aos seguintes temas: pensamento moderno e suas consequências na sociedade; Educação Ambiental; Interdisciplinaridade; a segunda ação emergiu do trabalho de campo na unidade educacional investigada.

A intenção foi mergulhar no cotidiano da escola com todos os sentidos como diria Alves (2003). A autora considera que para um estudo que pretenda investigar o cotidiano esco-

\footnotetext{
${ }^{2}$ Alves (2003) menciona ser esta, a grafia conjunta de termos, uma busca para a superação das "marcas que em nós estão devido à formação que tivemos dentro do modo hegemônico de pensar, representado pela ciência moderna, na qual um dos movimentos principais é a dicotomização desses termos, vistos como 'pares' mas opondo-se entre si” (p.2).
}

lar é preciso "ir além do que foi aprendido com estas particularidades e abstrações da modernidade, na qual o sentido da visão foi o exaltado" (p. 3).

Considerar tal proposta é buscar nos movimentos de pesquisa ir além da mera observação: é ouvir, sentir, intuir, os movimentos dos sujeitos ordinários (CERTEAU, 1994), que estão a produzir práticas dissimuladas, minuciosas no chão da escola.

A investigação se desenvolveu por intermédio de observação sistemática realizada uma vez por semana durante 4 horas, às terças-feiras. A escolha para o dia da semana na (terça-feira) se deu devido ao dia de permanência das aulas de Educação Física.

Como instrumento de produção de dados, utilizamos o caderno de campo para anotar as peculiaridades do cotidiano escolar e as idiossincrasias dos sujeitos em suas ações. Neste caderno de campo foram anotadas todas as informações peculiares para o desenvolvimento da pesquisa.

Para Mützenberg (2004), o caderno de campo tem a finalidade de registrar o desenvolvimento do trabalho de observação. O registro de atividades é organizado para que todos possam entender o seu conteúdo. Neste caderno o pesquisador transcreve suas percepções da realidade investigada. Investigamos as ações realizadas com os alunos do $1^{\circ}, 2^{\circ}$ e $3^{\circ}$ ano do Ensino Médio, totalizando 60 alunos.

Segundo SPINK (1993; 1994), quando se fala em objetividade na pesquisa qualitativa, dois elementos são considerados: a fidedignidade e a validade dos resultados obtidos. A autora apóia-se em KIRK e MILLER (1986) que distinguem três tipos de fidedignidade: a primeira seria a fidedignidade quixotesca que acontece quando o mesmo instrumento gera repetidamente a mesma informação; a segunda refere-se à fidedignidade diacrônica, associada à estabilidade da observação no tempo; e finalmente, a fidedignidade sincrônica, ou seja, aquela que inclui o uso de diferentes instrumentos e medidas. Segundo a autora é esta terceira modalidade que tem maior relevância na pesquisa qualitativa de 
fenômenos sujeitos à historicidade e dela resulta o uso de múltiplas técnicas e instrumentos para analisar o mesmo fenômeno.

Seguindo a perspectiva supracitada, optamos por utilizar outro instrumento para estudo e obtenção de dados da realidade: a entrevista. O roteiro foi construído com perguntas semi-estruturadas que foram realizadas com os docentes e discentes participantes do projeto de EA, as disciplinas de Educação Física, Biologia e História, além da direção e equipe pedagógica.

$\mathrm{Na}$ pesquisa utilizamos um roteiro com quatro perguntas abertas para os discentes e um roteiro com sete perguntas abertas para os docentes e equipe diretiva.

$\mathrm{Na}$ intenção de seguir as pistas deixadas pelos atores sociais em suas ações, utilizamos o Paradigma Indiciário de Carlo Ginzburg (1989), na intenção de cruzar os dados apreendidos das fontes mencionadas e articuladas aos documentos institucionais (Projeto Pedagógico, planejamentos de áreas e planos de aulas). O uso do Paradigma Indiciário permitiu encontrar sinais, pistas, indícios, fragmentos do 'modo' como os praticantes da unidade educacional pesquisada produzem a prática pedagógica de EA da referida instituição.

Cabe esclarecer que a pesquisa foi enviada ao Comitê de Ética do Instituto Federal do Rio de Janeiro (IFRJ) certificado sob o número 27091414.7.0000.5268.

\section{RESULTADOS E DISCUSSÃO DOS DA- DOS}

$\mathrm{Na}$ tentativa de compreender as práticas de Educação Física desenvolvidas no cotidiano da escola pesquisada, torna-se necessário explicitar o percurso trilhado pelos sujeitos que compõem a referida ação pedagógica. Para o entrelaçamento entre a Educação Física e Educação Ambiental, o grupo de alunos em concordância com o docente, optou pelo Esporte de Aventura como um conteúdo a ser desenvolvido, mais especificamente o Montanhismo. Em decorrência, decidiram pela realização de duas visitas técnicas, conforme dispostas a seguir: Parque Nacional do Itatiaia - RJ, mais especifi- camente no Planalto do Parque (conhecido como Prateleiras) e por fim, o Parque Lage localizado no Rio de Janeiro, na base do Corcovado.

\section{Montanhismo: Visita Técnica no Parque Na- cional de Itatiaia}

Segundo a ICMBio (Instituto Chico Mendes de Conservação da Biodiversidade) que é a instituição que administra o parque atualmente, o Parque Nacional do Itatiaia, que foi o primeiro Parque Nacional de Brasil, criado em junho de 1937. O parque é situado na Serra da Mantiqueira abrangendo os municípios de Itatiaia e Resende no Estado do Rio de Janeiro e Bocaína de Minas e Itamonte no Estado de Minas Gerais, onde ficam $60 \%$ de seu território. A unidade de conservação está localizada entre as cidades do Rio de Janeiro e São Paulo, bem próxima à Rodovia Presidente Dutra. $\mathrm{O}$ parque apresenta um relevo caracterizado por montanhas com altitude variando de $600 \mathrm{~m}$ a $2791 \mathrm{~m}$, no ponto culminante, o Pico das Agulhas Negras.

Na região do Planalto do Itatiaia, também conhecida como Parte Alta, encontram-se os campos de altitude e os vales suspensos onde nascem vários rios. A área do parque abrange nascentes de 12 importantes bacias hidrográficas regionais, que drenam para duas bacias principais: a do Rio Grande, afluente do Rio Paraná, e a do Rio Paraíba do Sul, o mais importante do Rio de Janeiro.

\section{Roteiro das aulas teóricas de Educação Físi-} ca:

$\mathrm{Na}$ intenção de promover a construção de conhecimentos que pudesse ser utilizado pelos alunos no momento da visita técnica, o professor de Educação física elaborou um roteiro de 3 aulas com conceitos e procedimentos necessários à atividade de Montanhismo proposta ao grupo de alunos.

$1^{\text {a }}$ aula: Trekking ${ }^{3}$ e Escalada Definição, equipamentos de segurança e alimentação adequada durante a prática do Montanhismo.

${ }^{3}$ Caminhada esportiva mais conhecida como enduro a pé. 
$2^{\text {a }}$ aula: Normas de segurança para a utilização do Parque Nacional do Itatiaia PRATELEIRAS e atitudes e comportamentos adequados em unidades de conservação.

$\mathbf{3}^{\text {a }}$ aula: MONTANHISMO - estratégias para diminuição de impacto ambiental.

Ao iniciarmos a ação de subida, em direção a Parte Alta do Parque - Prateleiras, observamos que os alunos realizavam as atividades em pequenos grupos, não permanecendo sozinhos ao longo do trajeto. Em conversa com o professor de Educação Física percebi que essa atitude havia sido trabalhada com os alunos como um pressuposto das atividades do projeto, na intenção de garantir a segurança e o desenvolvimento dos seguintes valores: cooperação, solidariedade e respeito mútuo.

É importante salientar que caminhamos aproximadamente durante 35 minutos para posteriormente realizarmos a primeira parada para o uso dos banheiros, descanso e lanche. Nesta parada nos encontrávamos a $2.300 \mathrm{~m}$ acima do nível do mar. O caminho ainda seria longo, mas a motivação do grupo em chegar ao topo das prateleiras se fazia perceber. O grupo descansou por 15 minutos aproximadamente e posteriormente prosseguiu.

Um aspecto que nos chamou atenção nos vários momentos de lanche foi a forma como os alunos se colocavam diante de tal ação: sempre dispostos a dividir tanto os alimentos quanto a água.

É importante frisar que mesmo nos momentos em que a água se tornava escassa a divisão era realizada com os que já não tinham. Assim, ressalto o princípio da solidariedade citada por Tristão (2005) como uma dimensão ética, que pode ser desenvolvida em ações de Educação Ambiental. Cabe salientar aqui que a solidariedade que buscamos enfatizar é aquela que emerge de uma "responsabilidade" e "respeito" recíproco com o coletivo, pois em uma parada a minha água serviu para alguns colegas do grupo, em outro momento pode ser que minha água acabe e eu dependa de outro colega

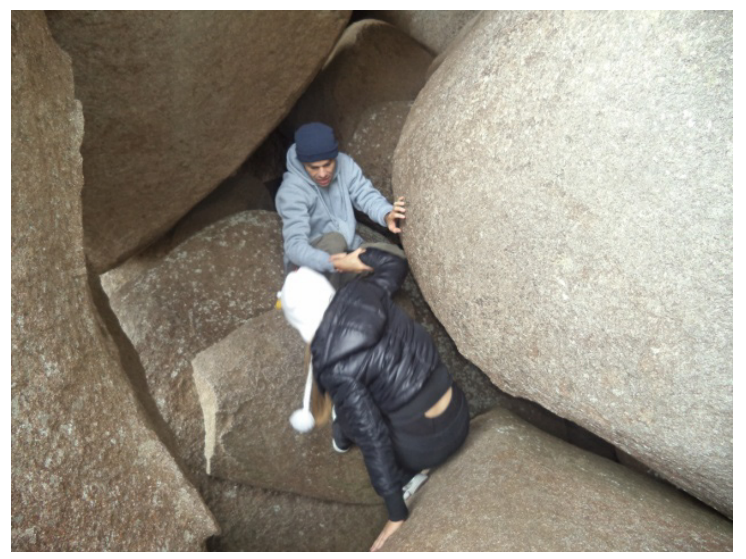

Figura 5 : [4] A solidariedade sempre presente nas atividades realizadas.

Outro aspecto a ser ressaltado foi o cuidado com o lixo que sempre era destacado pelos guias e professores. Os alunos guardavam todo o lixo na mochila que mais tarde seria descartado em local apropriado.

Do ponto onde estávamos - após a segunda parada para lanche - até as Prateleiras seriam ainda, segundo os guias, mais 50 minutos aproximadamente. No caminho encontramos alguns tótens, que são pedras colocadas uma em cima da outra como forma de marcar o caminho da volta. Estes tótens são indicadores de direção colocados por guias e funcionários do parque. É importante frisar que estes momentos de aprendizados sobre atitudes (marcar a volta, não modificar as marcações) na trilha fazem parte de uma série de comportamentos que se aproximam dos valores preconizados por educadores ambientais: respeito consigo mesmo, com os outros e com o meio em que está inserido, cooperação, solidariedade, respeito pelo coletivo, dentre outros.

É uma conquista pela dificuldade que é subir e depois ver esta vista linda que com pensa muito. (A. $2^{\circ}$ ano - depoimento anotado no caderno de campo).

O depoimento da aluna nos permite perceber a participação dos alunos na atividade e a importância do trabalho coletivo para que o grupo conseguisse alcançar o topo das Prateleiras:

[4] Figura do acervo do autor da pesquisa. 
Tem uma parte que é muito tranquila. Mas tem parte que tem muito abismo e você tem que segurar bastante. Em outra você tem que ter ajuda para subir. Tem hora que você não consegue. Foi bem difícil, mas é muito bom, pois quando você chegar lá em cima e vê a vista, vale muito a pena. O lugar é bonito. (M. $2^{\circ}$ ano - depoimento anotado no caderno de campo).

Neste momento gostaria de problematizar o depoimento da aluna, na qual a mesma cita a necessidade de auxílio de outros colegas para conseguir subir nas Prateleiras (Parque Nacional do Itatiaia). A intenção é refletir sobre a ação individualista muito comum na sociedade capitalista. Para Guimarães (2006, p. 28) os educadores ambientais devem exercitar a emoção como forma de desconstrução de uma cultura individualista extremamente calçada na razão e, portanto, vivenciar a construção do sentimento de pertencimento ao coletivo, ao conjunto, ao todo, representado pela comunidade e pela natureza.

O que busco frisar é que a atividade desenvolvida oferece essa possibilidade de intervenção, no entanto, na aula seguinte a visitatécnica, acompanhando o trabalho da disciplina de Educação Física, observamos que o docente não problematizou os problemas vivenciados pelos alunos. O professor durante a aula utilizou o computador e a internet, junto com os alunos, para exibir as fotos, os vídeos e analisar a visitatécnica, apenas do ponto vista da beleza cênica. Se considerarmos que Jordão (2009) menciona que:

Nas pesquisas que realizam na internet, por exemplo, os assuntos não seguem uma lógica com começo, meio e fim, mas surgem de conexões com outros assuntos, e estas conexões vão se ampliando até que os alunos estejam dispostos a prosseguir com suas pesquisas (p. 11).

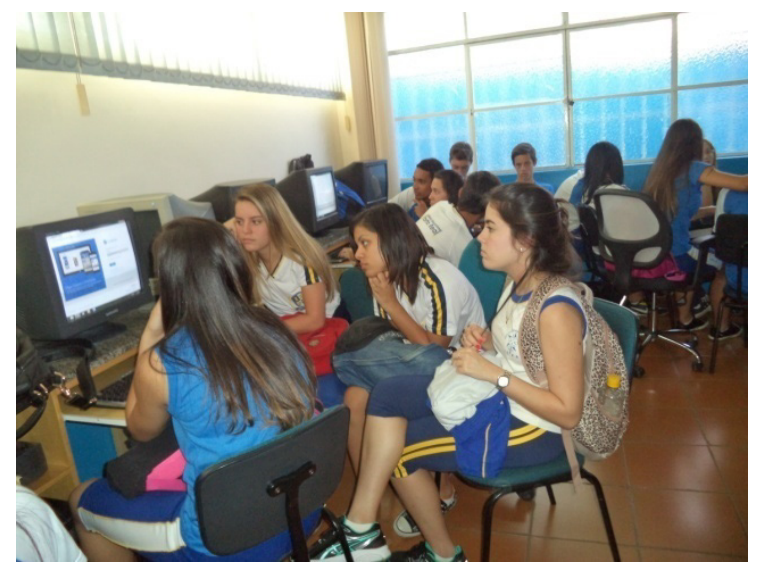

Figura 6: [5]Aula de Educação Física utilizando as tecnologias.

Considerando o exposto, seria interessante que em uma ação interdisciplinar e transversalizante o docente buscasse, conforme já explicitado, discutir as questões de EA que o coletivo considerasse significativo, neste momento o professor poderia ir tecendo os fios relacionados aos conceitos e noções de uma educação socioambiental.

Já a disciplina de Biologia, após a visita técnica, realizou por meio de atividades práticas a discussão. Os alunos mostraram as fotos produzidas e o apresentaram os dados observados por eles da flora, fauna, solo e intemperismo (vento, umidade e temperatura).

Novamente percebo que o docente de Biologia privilegia a perspectiva naturalista (SAUVÉ, 2005) em suas ações, pois o meio ambiente emerge apenas na ótica ecológica: da flora, fauna, solo e intemperismo (vento, umidade e temperatura). Os resultados sugerem a impossibilidade de trabalhar com o conteúdo proposto, mas a necessidade da tessitura de conhecimentos em rede (ALVES, 2008), percebemos que tais dados precisam ser significativamente pensados de acordo com a realidade vivida, portanto, considero que o professor poderia ter problematizado os dados obtidos para discutir a questão socioambiental por intermédio da crise hídrica.

A disciplina de História não apresentou as atividades realizadas após a visita técnica.

[5] Figura do acervo do autor do projeto. 
Prosseguindo o caminho metodológico do projeto da escola, é importante mencionar que depois das atividades de visita técnica, os professores se reuniam com a coordenação pedagógica para discutir as atividades que seriam realizadas em sala de aula com os alunos.

Neste momento busco a noção de interdisciplinaridade, que segundo JAPIASSÚ (1976), permite a troca entre os especialistas no interior de um mesmo projeto de pesquisa. Estas reuniões aconteciam entre a coordenação e os professores participantes após as visitastécnicas, já se iniciava o planejamento para a próxima atividade prática.

Pensando nas reuniões mencionadas recordo-me das observações de Guimarães (2011) em relação ao educador ambiental:

Sensibilizar o(a) educador(a) ambiental para uma permanente autoformação eclética, permitindo-lhe transitar das ciências naturais às ciências humanas e sociais, da filosofia à religião, da arte ao saber popular, para que se possa atuar como um interlocutor na articulação dos diferentes sabores (GUIMARÃES, 2011, p. 28).

Considerando o que o autor menciona, percebo que as reuniões permitiam o diálogo entre os professores e os diversos campos do saber, possibilitando a troca de conhecimentos entre os docentes. É importante frisar que os professores, no momento da reunião, também elaboravam as atividades de sala de aula que direcionavam as visitas técnicas a serem realizadas.

\section{Montanhismo: Visita-Técnica no Parque Lage/Corcovado}

O Parque Henrique Lage é um parque público da cidade do Rio de Janeiro, localizado aos pés do morro do Corcovado, à rua Jardim Botânico. Possui uma área com mais de 52 hectares e foi tombado pelo Instituto do Patrimônio Histórico e Artístico Nacional (IPHAN), em 14 de junho de 1957, como patrimônio histórico e cultural da cidade do Rio de Janeiro. Em 1859 a família Lage adquiriu no formato de compra e venda as terras onde se localiza o parque. No ano de 1859 o local passa a se chamar "Parque dos Lages" e em 1900 as terras passam para os filhos de Antônio Martins Lage que deixou como herança para os seus filhos. O parque recebe o nome de Henrique Lage, neto de Antônio Lage. Após assumir a administração das terras da família Henrique Lage realizou várias mudanças como construções e reformulações na propriedade.

\section{Roteiro das aulas teóricas de Educação Físi- ca: \\ $1^{a}$ aula: Normas de conduta no Parque Nacional da Tijuca e especificamente sobre a trilha Parque Laje Corcovado.}

$2^{a}$ aula: Histórico e curiosidades sobre o Parque Lage, Morro do Corcovado e a estátua do Cristo Redentor.

Devido ao tempo de aula e outras atividades do cotidiano escolar do instituto, a Educação Física só conseguiu ministrar duas aulas teóricas para a visita a ser realizada.

Antes de participarem da última visitatécnica os alunos realizaram uma apresentação dos objetivos das aulas de Educação Física. Os temas das aulas teóricas foram divididos para 2 grupos, no qual cada um ficou com o roteiro de uma aula para ler, analisar e apresentar para a turma.

\section{Roteiro das aulas teóricas de Biologia:}

Fazer um comparativo entre o ecossistema (campos de altitude e o Parque Lage). Fazer comparações por sensibilidade da temperatura, umidade e relacionar com a altitude. Fazer comparações com possíveis impactos ambientais que tenham percebido.

A disciplina de História não disponibilizou os planos de aulas.

Durante a atividade prática os alunos do $1^{\circ}$ ano observaram algumas condições solicitadas (fazer comparações por sensibilidade da temperatura, umidade e relacionar com a altitu- 
de) previamente pelo professor. Assim, através de quadros e tabelas os alunos apresentaram os impactos ambientais analisados durante a atividade em sala de aula.

O roteiro de aulas teóricas de História não foi disponibilizado para a pesquisa.

O professor de educação física reúne os alunos para as últimas instruções para a subida. É hora de ver se a garrafa de água está cheia, o lanche na mochila e ouvir as instruções necessárias para que nada aconteça errado. Passamos pela guarita para nos identificar. A identificação é condição necessária aos participantes que entram na trilha, pois é necessário informar a quantidade de pessoas que subirão pela trilha para que não cause muito impacto ambiental.

A trilha tem um grau de dificuldade, com extensão 2.240 metros, 704 metros de altitude e o tempo de subida são de $2 \mathrm{~h} 30 \mathrm{~min}$ em média. Mesmo assim, o grupo segue o caminho da trilha que nos levará em sua primeira parte nos trilhos do "bondinho" do Corcovado.

Ao iniciarmos a trilha no Parque Lage nos deparamos com a diversidade de plantas e com o cenário do ambiente visitado. Um dos espaços que provocou a curiosidade e o interesse dos alunos foi a gruta natural que cruza o nosso caminho. Neste momento percebi que houve um interesse muito grande dos alunos em adentrar a gruta. $\mathrm{O}$ professor de Biologia aproveitando deste momento realizou com os alunos uma aula expositiva sobre o cenário avistado, tendo o aluno participado de forma dinâmica (perguntando e respondendo) sobre a aula ministrada.

Seguimos o caminho dentro do Parque Lage, e nos deparamos com um aquário diferente em forma de árvore. Os alunos observam e se encantam com os peixes de várias espécies. Neste momento, percebo a Educação Ambiental Naturalista (SAUVÉ, 2005), em que o belo é mais admirado e privilegiado.

Para autora a proposição da corrente naturalista reconhece o valor intrínseco da natureza e centra suas ações na "Educação para Terra".

Prosseguindo na trilha novamente nos deparamos com a concepção Naturalista: os alunos e professores se depararam com um grupo de macacos que estavam no topo da árvore. O professor de Biologia fez as intervenções priorizando exclusivamente a flora e fauna local. A perspectiva naturalista apresenta uma ação educativa que convida os participantes a viverem experiências cognitivas e afetivas em um meio natural (SAUVÉ, 2005). Após as explicações do professor sobre o Macaco Prego e o seu habitat natural seguimos rumo à trilha.

Seguimos o caminho da trilha que é marcada com setas e placas nos levando para um lugar ainda desconhecido pelo grupo. Na subida vários avisos para que façamos sempre o percurso indicado pela direção do parque. Com o transcorrer do percurso, parte dos alunos começa a sentir o cansaço da subida. O grupo é dividido em 3 (três). O primeiro grupo que segue em disparada. O segundo grupo que vem aproveitando as belezas naturais. E o terceiro grupo que sobe mais devagar em decorrência do cansaço. No entanto, isso não impede que todos percorram a trilha. Com isso o projeto reforça a dimensão política (participação) citado por Tristão (2005), onde demonstra que mesmo um grupo mais lento, ele tem condições de participar da atividade.

Chegamos numa etapa que fica mais íngreme. A dificuldade e o esforço físico aumentam. Mesmo assim o grupo continua. Os descansos agora são mais frequentes e os alunos descansam mais tempo para uma maior recuperação física. Os professores neste momento aproveitam para dar explicações sobre os conteúdos de cada disciplina e a EA. Já estamos exaustos e desistir já passa pela cabeça de alguns. Um começa a ajudar o outro, seja na divisão do lanche, da água ou até mesmo ajudando os que possuem mais dificuldade para subir. A dimensão ética (solidariedade) e a dimensão política (a participação) de Tristão (2005) aparecem para confirmar o que em todos os momentos acontece na atividade. 


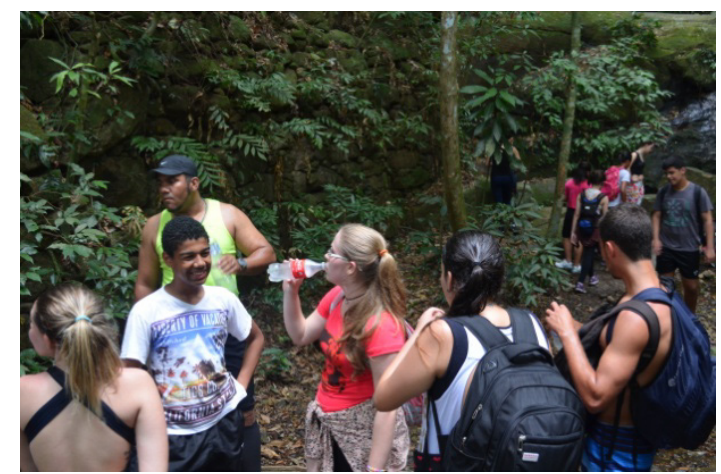

Figura 7: [6] Nos descansos a divisão da água acontece em vários momentos.

Eu vim de outra escola e eu nunca tive a oportunidade de realizar uma atividade como esta (W., 15 anos, $1^{\circ}$ ano, depoimento anotado no caderno de campo).

Tristão (2005) ressalta sobre prazer, autoria e artefactualidade discursiva, em que o aluno cita não ter participado de um projeto sobre EA. E com muita solidariedade vamos subindo com a ajuda do outro e diminuindo assim a possibilidade de alguém desistir. Pelo caminho vamos encontrando "aventureiros" subindo e descendo. São americanos, ingleses, argentinos, espanhóis e brasileiros.

Chegamos numa das partes mais difíceis, a subida da corrente. Nesta subida existe um trecho com correntes fixadas nas pedras para nos auxiliar. Os alunos estão exaustos, o primeiro grupo já se distanciou. Mas mesmo com as divisões dos grupos, ainda existe o apoio e o não abandono na subida dos colegas. Os alunos permanecem juntos dentro dos subgrupos. Como é a primeira vez na trilha não temos a noção se está chegando ou não a segunda parada. Depois das correntes são mais aproximadamente 60 metros até os trilhos do "bondinho" para que possamos descansar, recuperar a energia e lanchar.

Até chegar aos trilhos foram 1h30min desde o início da trilha. O primeiro grupo que chegou viu dois "bondinhos" passar que partem a cada 20 minutos do local de embarque.

[6]Figura do acervo do autor da pesquisa.
A dificuldade própria que tivemos foi a de escalada, mas foi bem legal. A subida foi difícil tem muitas pedras, tem parte que escorrega e tem parte que temos que ficar esticando a perna até alcançar [...]. (C., 16 anos, $2^{\circ}$ ano, depoimento anotado no caderno de campo).

O depoimento da aluna demonstra mais uma vez a dimensão política (a participação) e a dimensão estética (o reencantamento) de Tristão (2000), quando a discente cita que a atividade "foi bem legal". Fizemos o lanche, nos hidratamos e descansamos. É nítido o cansaço. Os meninos ajudam as meninas que ficaram para trás. Sempre existe num grupo de meninas, pelo menos um menino para ajudá-las e andar juntos.

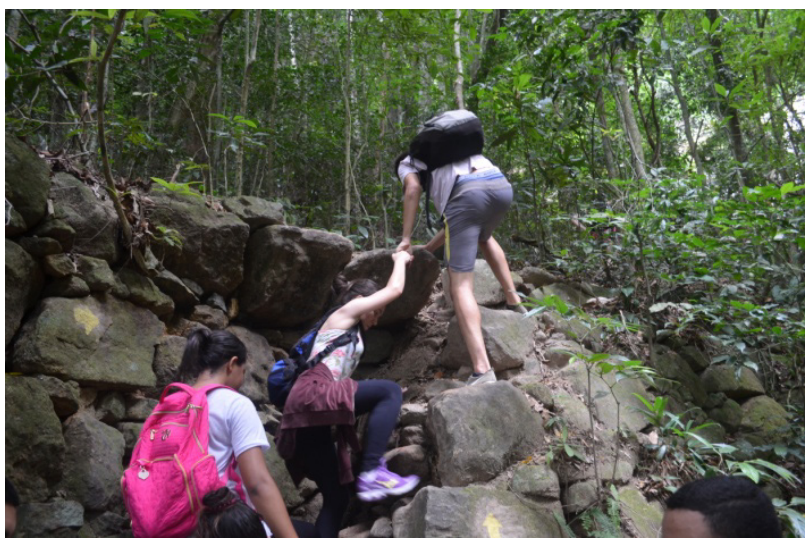

Figura 8: [7]Meninos e meninas sempre juntos se solidarizando.

Subimos aproximadamente mais 100 metros e chegamos à pista de subida das Paineiras, local de onde as Vans passam para levar os turistas ao Corcovado. Saímos da trilha agora a estrada é de asfalto. Começamos a ver a cidade do Rio de Janeiro, mesmo com uma grande neblina conseguimos visualizar partes da cidade. Percorremos no asfalto cerca de 150 metros até chegarmos ao nosso destino: o morro do Corcovado.

Uma das primeiras visões que temos do Rio de Janeiro é parte do Maracanã com pouca visibilidade devido ao nevoeiro. $\mathrm{O}$ topo do morro permite uma vista panorâmica da cidade do

[7] Figura do acervo do autor da pesquisa. 
Rio de Janeiro, do Pão de Açúcar, das praias de Copacabana e Ipanema, Lagoa Rodrigo de Freitas, do Hipódromo da Gávea bem destacado, da praia do Leblon, da Enseada de Botafogo, do Aterro do Flamengo, do Maracanã e de bairros e comunidades próximas das zonas sul, norte e central da cidade.

É hora de descer. Das paineiras em diante descemos a pé numa fila indiana devido ao intenso tráfego de veículos.

$\mathrm{Na}$ descida encontramos ainda lixo jogado por turistas, os alunos e professores foram recolhendo as garrafas e potes plásticos jogados no chão para colocarem nas latas pelo caminho da descida.

Como existia um grupo de alunos todos juntos que desceriam a pé, muitas pessoas perguntavam o que tantos adolescentes faziam naquele local. Quando os alunos diziam que estavam realizando uma atividade sobre EA, as pessoas perguntavam qual a escola e de qual cidade eram, o que despertava a visibilidade da atividade desenvolvida.

Nesse momento me recordo da Sociologia das Ausências que propõe (SANTOS, 2000, p. 29) a visibilização das práticas cotidianas, pois muitas delas são consideradas inexistentes.

Posteriormente à visita os alunos ainda tiveram uma aula sobre EA em que foram discutidos os resultados obtidos nas visitas técnicas, por meio da apresentação de trabalhos.

Diante do exposto, cabe frisar que percebo o projeto ambiental pesquisado configurado pelas contradições que marcam a sociedade capitalista, com suas tensões, conflitos e interesses. O que busco ressaltar é que ao mergulharmos (ALVES, 2001) no cotidiano da escola, encontramos indícios (GINZBURG, 1989) de ações que buscam se contrapor ao modelo de comportamento proposto pelo modo de produção capitalista: solidariedade, cooperação, construção coletiva.

Em contrapartida não percebi os docentes problematizando no cotidiano de suas atividades tais contradições o que revela sinais (GINZBURG, 1989) de uma EA conservadora.
$\mathrm{Na}$ EA conservadora o "homem" (ser) é o principal acusado de "usar" a natureza a seu favor, retirando os seus elementos para a sobrevivência de sua espécie. Em muitos momentos fui remetido a lembrar da corrente conservacionista mencionada por Sauvé (2005). Tal corrente agrupa suas proposições apenas na conservação dos recursos, direcionando-se a uma ótica de administração do ambiente ou de gestão ambiental.

Em outros momentos percebi que o mais relevante no projeto emergia da estética e da beleza cênica, mostrar as belezas naturais, o que é importante, pois segundo Tristão (2005) existe um reencantamento do aluno quando visita locais de áreas verdes, como citado em vários momentos nesta pesquisa. Porém, este (beleza cênica) deve ser considerado um ponto de partida, para posteriormente romper com a Armadilha Paradigmática (GUIMARÃES, 2011), "percebendo, problematizando e complexificando os antagonismos e complementaridades da realidade em suas múltiplas determinações materiais, epistemológicas, culturais" (p. 26). Percebi que no trabalho a comunidade local não participou das ações do cotidiano escolar e que poderia ter sido inserida.

Para finalizar, percebo que o projeto se configura na tensão entre a ruptura e a reprodução de um modelo configurado pelo modo de produção capitalista, mas se aproxima de uma pedagogia que busca as singularidades dos sujeitos que vivenciam tal espaço (alunos, docentes, coordenadores pedagógicos, direção) nos remetendo a pensar o currículo pensadopraticado (OLIVEIRA, 2012), currículo que entrelaça às propostas oficiais, mas respeita a particularidade local para daí tornar significativas as formas de ensinar e aprender.

\section{CONSIDERAÇÕES}

O projeto de EA investigado parte da disciplina de Educação Física e possui como característica a interdisciplinaridade como proposta de ação. Durante a pesquisa busquei entender o cotidiano do projeto mergulhando no 
cotidiano do Instituto Educacional Porto Real na intenção de acompanhar processos e conhecer as práticas que acontecem na referida escola, tendo o tema de EA como centralidade.

Considerando que um dos objetivos do estudo foi compreender as práticas educativas relacionadas a EA, buscamos, por meio da Sociologia das Ausências (2007) visibilizar as ações dos sujeitospraticantes (professores, alunos, direção) envolvidos no trabalho de EA do Instituto Porto Real, como prática pedagógica, que desperta a participação, a solidariedade e o reencantamento pelo meio ambiente.

Outro aspecto relevante a salientar, como resultado deste trabalho e da sociologia proposta, é a contribuição do trabalho que se coloca como um contraponto, problematizando práticas educativas em EA, possibilitando o diálogo com outras produções e provocando aberturas para debates e críticas que despertem o interesse para uma cultura muito além da proteção ambiental.

Neste sentido, é relevante ressaltar que a escola possui um papel importante no processo de possibilitar o diálogo e a troca de ideias por intermédio dos projetos desenvolvidos.

Para finalizar, ressalto a ruptura do projeto com a ótica de educação bancária, pois busca ir para além dos muros da escola, caracterizando uma ação didática que contempla uma educação que não fixa sua centralidade no quadro, no giz e na figura emblemática do professor, mas possui o potencial de centralizar as suas ações nos alunos e na problematização dos conflitos encontrados se aproximando de um processo de ensino e aprendizagem significativos.

\section{REFERÊNCIAS}

ALVES, N. Sobre Movimentos das Pesquisas nos/dos/com os cotidianos. Teias: Rio de Janeiro, ano 4, no 7-8, jan/dez 2003. Disponível em: $\quad$ www.periodicos.proped.pro.br/index. php?journal=revistateias\&page, Acesso em: 20 Maio 2014.
Decifrando o pergaminho - o cotidiano das escolas nas lógicas das redes cotidianas. In OLIVEIRA, I. B. de e ALVES, N. Pesquisa no/ do cotidiano das escolas - sobre redes de saberes. Rio de Janeiro: DP\&A, 2001.

Sobre o movimento das pesquisas nos/dos/com os cotidianos. In: OLIVEIRA, Inês Barbosa; ALVES, Nilda. (Orgs.). Pesquisa no/do cotidiano das escolas: sobre redes de saberes. Petrópolis: DP et Alii, 2008.

ALVES, R. F. BRASILEIRO. M. do C. E.BRITO. S. M. de O. Interdisciplinaridade: um conceito em construção. Episteme, v. 19, n. 02, 2004.

BAUMAN, Z. Comunidade. Rio de Janeiro: Jorge Zahar Editora, 2003.

BOHR, Niels Henrik David. Física atômica e conhecimento humano - ensaios 1932- 1957. Tradução: Vera Ribeiro. Rio de Janeiro: Contraponto, 1995.

BRASIL. Secretaria de Educação Fundamental. PARÂMETROS CURRICULARES NACIONAIS: TERCEIRO E QUARTO CICLOS DO ENSINO FUNDAMENTAL: INTRODUÇÃO AOS PARÂMETROS CURRICULARES NACIONAIS/Secretaria de Educação Fundamental. - Brasília: MEC/SEF, p. 174, 1998.

BRASIL. PARÂMETROS CURRUCULARES NACIONAIS: Ensino Médio. Ministério da Educação. Brasília, 1999.

CERTEAU, M. A invenção do cotidiano: artes de fazer, 3. ed, Petropólis/RJ: Vozes, 1994.

CARVALHO, I. C. de M. Educação ambiental: a formação do sujeito ecológico, 5. ed, São Paulo: Cortez, 2010.

COIMBRA, J. de A. A. Interdisciplinaridades em Ciências Ambientais, In PHILLIPI Jr. A. Interdisciplinaridade em Ciências Ambientais / A. 
PhilippiJr., C. E. M., TUCCI, D. J., HOGAN, R. N. São Paulo: Signus Editora, Vários colaboradores, 2000.

COLOMBO, S. R. A Educação Ambiental como instrumento na formação da cidadania. Revista Brasileira de Pesquisa em Educação em Ciências, v. 14, no 2, 2014.

CORDIOLLI, M. Para entender os PCNs: Os temas transversais. Curitiba: Módulo Editora, 1999.

FAZENDA, I. C. A. Interdisciplinaridade: História, Teoria e Pesquisa. 11. ed., São Paulo: Papirus, 1994.

FAZENDA, I. C. A. Integração e interdisciplinaridade no ensino brasileiro: efetividade ou ideologias. 5.ed. São Paulo: Edições Loyola, 2002.

FREIRE, P. Pedagogia do oprimido. 27 ed. Rio de Janeiro: Paz e Terra, 1987.

FERRAÇO, C. E. Pesquisa do cotidiano. Educ. Soc., Campinas/SP, v. 28, n. 98, p. 73-95, jan./ abr. 2007. Disponível em: http://www.scielo.br/ pdf/es/v28n98/a05v2898.pdf, Acesso em: 18 Ago 2014.

HENRY, J. A revolução científica e as origens da ciência moderna. Rio de Janeiro: Jorge Zahar Ed., 1998.

GALLO, S. Transversalidade e educação: pensando uma educação não-disciplinar. In ALVES, N. GARCIA, R. L. (orgs.) O Sentido da Escola. Rio de Janeiro: DP\&A, 2000.

. Currículo (Entre) imagens e saberes. In: CONGRESSO INTERNACIONAL DE EDUCAÇÃO. 5.ed, 2007, São Leopoldo. Painel. São Leopoldo: UNISINOS, 2007.

. Acontecimento e resistência: educação menor no cotidiano da escola. In: CAMARGO
A. M. F. MARIGUELA M. (orgs.). Cotidiano escolar: emergência e invenção. Piracicaba: Jacintha Editores, 2007.

. GALLO, S. Conhecimento, transversalidade e currículo. In: REUNIÃO ANUAL DA ANPED, 24. Programa e resumos. Associação Nacional de Pós-Graduação e Pesquisa em Educação, 1995. p.97.

GARCIA, L. A. M. Transversalidade e interdisciplinaridade. Brasília, 2005, Disponível em: www ensino.net, Acesso em: 23 Jun 2013.

GIDDENS, A. As consequências da modernidade. São Paulo: Editora UNESP, 1991.

GINZBURG, C. Sinais: raízes de um paradigma indiciário. In . Mitos, Emblemas e Sinais: morfologia e história. São Paulo: Cia das Letras, 1989.

GUIMARÃES, M. A formação de educadores ambientais. Campinas: Papirus, 2004(a).

GUIMARÃES, Mauro. Educação ambiental crítica. Identidades da educação ambiental brasileira. Brasília: Ministério do Meio Ambiente, p. 25-34, 2004(b).

GUIMARÃES, M. Armadilha Paradigmática na Educação Ambiental, In: LAYRARGUES, P. P., CASTRO, LOUREIRO, R. S. LOUREIRO, C. F. B., Pensamento complexo, dialética e educação ambiental. 2. ed. São Paulo: Cortez, 2011.

GUIMARÃES, M., VASCONCELLOS, M. das M. N. Relações entre educação ambiental e educação em ciências na complementaridade dos espaços formais e não formais de educação, Educar em Revista. Educ. rev. n. 27, Curitiba Jan/Jun 2006. Disponível em: http://www. scielo.br/scielo.php?script=sci_arttext\&pid =S0104-40602006000100010, Acesso em: 20 Out 2014.

JACOBI， P. R. TRISTÃO, M. FRANCO, 
M. I. G. C. A função social da educação ambiental nas práticas colaborativas: participação e engajamento. Caderno Cedes. Campinas, v.29, n.77, jan./abr. 2009. Disponível em: http://www.scielo.br/scielo.php?script=sci arttext\&pid=S0101- 32622009000100005\&lng $=$ pt\&nrm=iso\&tlng=pt, Acesso em: 05 Set 2014

JORDÃO, T. C.BRASIL. Secretaria de Educação à Distância, Tecnologias Digitais para a Educação: A formação do professor para a educação em um mundo digital. Brasília, 2009.

KIRK, J. \& MILLER, J. Reliability and validity in qualitative research. Beverly Hills, Califórnia: Sage, apud SPINK, M.J.P. 1993. O estudo empírico das Representações Sociais. In: SPINK, M.J.P. (org.) O Conhecimento no Cotidiano: as representações sociais na perspectiva da psicologia social. São Paulo: Brasiliense, 1986.

KRASILCHIK, M. ARAÚJO, U. F. Novos caminhos para a educação básica e superior. São Paulo: Artigo, p. 01, EACH/USP, 2010.

LEFF, E.A complexidade ambiental. 2. ed., São Paulo, Cortez, 2010.

LOUREIRO, C. F. B. Educação Ambiental repensando o espaço da cidadania. In LAYRARGUES, P. P. CASTRO, R. S. de (orgs.), Pensamento complexo, dialética e Educação Ambiental. São Paulo: Ed. Cortez, 2011.

LOUREIRO, C. F. B. Problematizando conceitos de contribuição à práxis em Educação Ambiental. In LOUREIRO, C. F. B. LAYRARGUES, P. P., CASTRO, R. S. de (orgs.), Pensamento complexo, dialética e Educação Ambiental. São Paulo: Ed. Cortez, 2011.

LEBERT, G. Transdisciplinaridade e Educação. In: MORIN, E. A religação dos saberes: o desafio do século XXI. Rio de Janeiro: Bertrand Brasil, 2002.
LÜCK, H. Pedagogia interdisciplinar. Fundamentos teórico-metodológicos. Petrópolis: Vozes, 1994.

MARCONI, M. de A., LAKATOS, E. M. Metodologia do Trabalho Científico. 7. ed., São Paulo: Atlas, 2010.

MARINHO, A. Natureza, tecnologia e esportes: novos rumos. Conexões: Educação, Esporte e Lazer.v. 1, n. 2, Unicamp, Campinas/SP, 1999.

MIRANDA, Jean Carlos. Sucessão ecológica: conceitos, modelos e perspectivas. SaBios-Revista de Saúde e Biologia, v. 4, n. 1, 2009.

MORIN, E. Introdução ao pensamento complexo. Lisboa: Instituto Piaget, 1990.

MÜTZENBERG, L. A. Mestrado profissional em física: Guia do Aluno. UFRGS, 2004, Disponível em: http://www.if.ufrgs.br/mpef/Hipermidias/Mutzenberg/arq/g_alu_txt.htm, Acesso em: 17 Ago 2013.

MOREIRA, H., CALEFFE, L. G. Metodologia da pesquisa para o professor pesquisador. Rio de Janeiro: DP\&A, 2006.

OLIVEIRA, I. B. de. Contribuições de Boaventura de Souza Santos para a reflexão: princípios emancipatórios e currículos pensadospraticados. Revista e-curriculum, São Paulo, v.8 n. 2

AGOSTO 2012. Disponível em: http://revistas. pucsp.br/index.php/curriculum, Acesso em: 01 Set 2014.

PAIVA, A. C. de; FRANÇA, T.L. de. Trilhas interpretativas: reconhecendo os elos com a educação física. Revista Brasileira de Ciências do Esporte. Campinas, v. 28, n. 3, p.109-124, 2007.

SAUVÉ, L. Uma cartografia das correntes em educação ambiental. In SATO, M.; CARVALHO, I. (orgs). Educação ambiental: pesquisa e desafios. Porto Alegre: Artmed, p. 17-44, 2005. 
SANTOS, B. de S.A crítica da razão indolente: contra o desperdício da experiência. 4 ed. São Paulo: Cortez, 2002.

Para uma sociologia das ausências e uma sociologia das emergências. In: SANTOS, B. de S. (org.). Conhecimento prudente para uma vida decente: um discurso sobre as ciências revisitado. São Paulo: Cortez, 2004.

- A gramática do tempo: para uma nova cultura política. São Paulo: Cortez, 2006.

$\neg \neg \neg$ . Renovar a teoria critica e reinventar a emancipação social. São Paulo: Boitempo, 2007.

. Um discurso sobre as ciências. 7. ed., São Paulo: Cortez, 2010.

. Para uma pedagogia do conflito. In: SILVA, L. H., AZEVEDO, J. C. de SANTOS, E. S. dos. Novos mapas culturais, novas perspectivas educacionais. Porto Alegre, p. 15-33, 1996.

SIQUEIRA, H. S. G. Pós modernidade, política e educação: a condição pós-moderna e suas implicações na construção de uma educação pósmoderna crítica. Tese (Doutorado em Educação) PPGE/USM. Santa Maria, RS, 2003.

SPINK, M.J.P. O Conceito de Representação Social na Abordagem Psicossocial. Cadernos de Saúde Pública. v.9, n.3, pp.300-308, 1993. Disponível em: http://www.scielo.br/pdf/csp/ v9n3/17.pdf, Acesso em: 12 Fev 2014.

. Desvendando as teorias implícitas: uma metodologia de análise das Representações Sociais. In: JOVCHELOVITCH, S. e GUARESHI, P. (orgs.) Textos em Representações Sociais. Petrópolis: Vozes, 1994.

SUASSUNA, A. Iniciação à estética. Rio de Janeiro: José Olympio, 2008.

TRISTÃO, M. Narrativas de educação ambien- tal em contextos praticados, vividos e constituídos. 2009. Disponível em: http://www.anpae. org.br/congressos_antigos/simposio2009/252. pdf, Acesso em: 01 Jul 2014.

. Tecendo os fios da educação ambiental: o subjetivo e o coletivo, o pensado e o vivido. 2005. Disponível em: http://www.scielo.br/pdf/ep/v31n2/a08v31n2.pdf, Acesso em: 25 Ago 2014.

. Os Contextos da Educação Ambiental no cotidiano: racionalidades da/na escola. 2007. Disponível em: http://www.ambiente. sp.gov.br/wp-content/uploads/cea/Contextos EA.pdf, Acesso em: 14 Jun 2014.

VIEIRA, V. Desenvolvimento de um instrumento de identificação de impactos ambientais em práticas esportivas na natureza (impacambes). Dissertação (Mestrado em Ciências da Motricidade Humana) Universidade Castelo Branco. PPGCMH/UCB, Rio de Janeiro, 2004.

ZACARIAS, R. Sociedade de consumo, ideologia do consumo e iniqüidades socioambientais dos atuais padrões e consumo. In LOUREIRO, C. F. Bernardo; LAYRARGUES, P.P., CASTRO, R. de S. Repensar a Educação Ambiental: um olhar crítico. São Paulo: Cortez, 2009. 